\title{
HEPATITIS Y EMBARAZO
}

\author{
Dr. Luis Armando Muñoz G.* \\ Dr. Adolfo Martinez S.**
}

\section{Generalidades}

Es una afección producida por un virus, que algunos encuentran parecido al de la Poliomielitis (1). Se conocen en general dos tipos de virus, que ocasionan formas clínicas diferentes:

1) $\mathrm{JH} \circ$ virus $A$, responsable de la Hepatitis infecciosa, cuya vía de transmisión, especialmente es la digestiva y se aisla de la sangre y materias fecales de los enfermos que padecen la afección. Tiene un período de incubación de 2 a 6 semanas. Puede existir el antecedente de contagio previo.

2) $\mathrm{SH}$ ○ virus $\mathrm{B}$, responsable de la Hepatitis a suero homólogo; aparece en la sangre y tejidos de las personas afectadas. Su período de incubación varía entre 6 semanas a 6 meses y se puede encontrar el antecedente de aplicación de sangre, plasma, suero, fibrinógeno, vacunas o inyecciones.

Es importante recalcar que no hay inmunidad cruzada entre estos dos tipos de virus $(2,3,7)$.

\section{Frecuencia}

Se dice que la enfermedad se observa especialmente clurante la preñez (15), y algunos afirman que de todas las mujeres que presentan es- ta entidad el $50 \%$ son embarazadas (1).

Según Zondek (18), quien estudió 3.382 mujeres embarazadas, encontró una incidencia de 0,8\%.

Vincent (15), revisó 136.000 embarazadas; 32 de ellas tenían ictericia, correspondiendo a Hepatitis por virus 23 casos.

Martini (9), da una incidencia de $0,04 \%$ en estudio realizado sobre 91.000 pacientes embarazadas.

En el Lyingin Hospital de Chicago, en 72.000 embarazos, sólo se encontró 10 casos (15).

Una revisión de 12 años (19281940) en Rigs-Hospitalet de Copenhagen se registraron 15 casos (15).

En el Instituto Materno Infantil (IMI) de Bogotá, en los diez últimos años (1959-1968) sobre un total de 217.222 pacientes embarazadas, encontramos 10 casos de Hepatitis viral comprobados por laboratorio.

Los datos obtenidos se discriminan así:

* Instructor asistente. Facultad de Medicina, Universidad Nacional (Colombia). Depto. de Ginecología y Obstetricia.

** Residente de Tercer año. Departamento de Ginecología y Obstetricia. Universidad Nacional. 


\section{Edad}

La edad osciló entre 19 a 38 años, con un promedio de 28,9 .

\section{Paridad}

Con menos de 2 gestaciones: 2 pacientes.

Con 4 o más gestaciones: 8 pacientes.

\section{Edad gestacional}

Entre 10:-18a semana (etapa de aborto): 5 casos.

Entre 27:-36: semana (etapa de inmadurez y prematurez): 4 casos. caso.

En la 39a semana (a término): 1

\section{Contagio}

Solo en un caso se determinó claramente antecedente de contagio en la casa; se anota que dos familiares padecían la enfermedad, uno de ellos falleció dias antes al ingreso de la paciente.

\section{Estancia hospitalaria}

En promedio: 21,4 días.

\section{Comportamiento del estado gravídico ante la hepatitis}

Se cree que el embarazo no sólo agrava sino que predispone a la erıfermedad, especiaimente cuando se adquiere en la segunda mitad de la gestación. Este es el concepto dominante de los autores revisados (1, $-U)$, sin embargo otros Harriton (7), Trorling (17) sostienen que la enfermedad tiende a seguir un curso benigno.

En el presente estudio se observó evolución satisfactoria en 7 casos de los 10 anotados y se presentó una defunción.

\section{Comportamiento de la hepatitis ante el estado gravídico}

No existe actualmente uniformidad de criterios, para asegurar que el virus produzca embriopatías, como sucede con otras virosis (sarampión, varicela, mononucleosis infecciosa, rubeola, gripe, herpes zoster) (10). Sherlock (16), ha sugerido que el feto está protegido contra el virus, por las gammas-globulinas de la sangre materna. Ocasionalmente la madre puede transmitir al feto la infección, cuando ella la padece en el último trimestre; se puede apreciar en el recién nacido los signos de la enfermedad; ésta evoluciona en forma benigna como es la regla, o en forma grave llegando a la cirrosis como secuela tardía.

Con mayor frecuencia se observa que esta afección determina: abortos, partos prematuros y muerte fetal in útero (10).

En el presente estudio encontramos:

Aborto: 2 casos (20\%).

Parto prematuro: 2 casos (20\%).

Muerte fetal in útero: 1 caso 10\%.

Los 5 casos restantes ( $50 \%$ ) terminaron con fetos vivos a término, sin evidencia de lesiones congénitas y aparentemente sanas.

\section{Curso del parto}

Es frecuente observar que las pacientes ictéricas presentan un trabajo de parto rápido, caracterizado por contracciones uterinas de mayor intensidad y frecuencia (13); lo cual hace presumir una sensibilización del músculo uterino a los niveles altos de 
ácidos biliares. Como consecuencia de lo anterior puede aparecer hipertonía uterina, sufrimiento fetal y abruptio placentae entre otras complicaciones.

En nuestra serie revisada no se observó este fenómeno. Debemos advertir que sólo dos pacientes presentaron el parto cuando tenían la enfermedad y las restantes la habían adquirido en la primera mitad del embarazo.

\section{Alumbramiento}

En este período del parto puede ocurrir hemorragia copiosa, sin que esto sea frecuente $(10,15)$.

En la presente revisión se observó un caso con esta complicación y que corresponde a la paciente cuya enfermedad siguió un curso grave, falleciendo tres días después del parto.

\section{Síntomas}

Se catalogan de acuerdo a las tres etapas que presenta el cuadro clíni$\mathrm{co}$ :

A. Fase Pre-ictérica. Predominan en ella la fiebre, trastornos gastrointestinales, (anorexia, náuseas, vómito, diarrea, molestias abdominales) coluria, astenia, adinamia, enfermedad respiratoria alta, aversión al fumar etc. tiene una duración de pocos días a una semana.

B. Fase Ictérica. Cursa con o sin fiebre. En ella se puede observar además de la ictericia, hepatomegalia dolorosa y acolia. Generalmente después de este período sobreviene la recuperación, pero algunos casos evolucionan a una etapa posterior, que es el período terminal, en el cual se encuentra oliguria, albuminuria, cilindruria, hematuria, somnolencia, delirio y finalmente el coma que puede conducir a la muerte $(3,7,10)$.
En la casuística del Instituto Materno Infantil (IMI), los síntomas en orden de frecuencia fueron:

Fiebre $70 \%$.

Ictericia $60 \%$.

Coluria $50 \%$.

Malestar general $50 \%$.

Anorexia $40 \%$.

Vómito $40 \%$.

Acolia $40 \%$.

Es fácil comprender por los síntomas anteriores que las pacientes consultan en una fase avanzada de la enfermedad.

\section{Laboratorio}

En la Hepatitis viral, es quizás donde el laboratorio juega un papel primordial en el diagnóstico definitivo, permitiendo diferenciarla de cuadros como síntoma predominante; esto es aún más cierto en la mujer embarazada en donde es sabido suele presentarse con más frecuencia la lctericia Idiopática, la Obstructiva y aun la Tóxica, especialmente en nuestro medio por ingestión de fósforo blanco.

\section{Así tenemos que en la: (13)}

1. Ictericia idiopática y obstructiva, los niveles de Bilirrubina se encuentran aumentados a expensas de la Directa, mientras que en la Hepatitis viral estarán aumentados tanto en la Directa como en la Indirecta.

2. Fosfatasa Alcalina: aumentada principalmente en la Ictericia Obstructiva.

3. Transaminasas: Tendencia a elevarse en todas las formas de Hepatitis, siendo las cifras más altas en la Viral y Tóxica.

4. Test de Turbidez del Timol y Proteínas Séricas: son normales en todas las formas de ictericia. 
5. Colesterol total: no se aprecia variación en diferentes formas.

6. Hierro Sérico: los niveles aumentan en la ictericia Idiopática, Tóxica y Viral; no sufre modificación en la Obstructiva.

7. Acido Urico: se eleva en todas las formas de ictericia.

8. Creatinina: no sufre cambio en los distintos tipos de ictericia.

9. Tiempo y Actividad de Protrombina: está en relación directa con la función hepática, por lo tanto se encontrará más alterada en la Hepatitis Viral y Tóxica.

10. Aparte de las pruebas de funcionamiento hepático, tiene importancia el cuadro hemático; mostrará número de leucocitos normlaes o disminuídos, a veces con aumento relativo de eosinófilos o linfocitos. En ocasiones la linfocitosis relativa se presenta con formas anormales (3).

En la serie objeto de este estudio, los exámenes practicados y sus resultados fueron:

1. Bilirrubinas. (cifras promedios)

a. Directa total 5,9 mgrs.

b. Indirecta 2,5 mgrs.

2. Fosfatasa Alcalina.

No se encontró aumento significativo. Promedio 6,5 U.B.

3. Transaminasas.

Los valores extremos oscilaron:

SGOT 2.620 - $230 \mathrm{U}$.

SGPT 1.060 - $190 \mathrm{U}$.

4. Turbidez del Timol.

El valor medio hallado fue de: 4,9.

5. Proteínas.
El promedio: 5,6 mgrs. \%. No hubo inversión de la fórmula.

6. Creatinina.

Sus niveles estuvieron dentro de límites normales, con cifra promedio de: 0,9 mgr. $\%$.

7. Tiempo y Actividad de Protrombina.

En el $70 \%$ de las pacientes, la Actividad fué de $70 \%$ y en el resto de $100 \%$.

8. Cuadro Hemático. No hubo modificaciones atribuíbles a la enfermedad. Se observó leucocitosis en dos casos que corresponde a pacientes con patología sobreagregada.

9. Resto de exámenes de laboratorio, no fueron practicados.

Los hallazgos de laboratorio concuerdan con los estudios de los autores consultados $(2,3,7,12)$.

Es importante anotar que en sí el laboratorio de la Hepatitis no sufre modificaciones cuando a ella se suma el embarazo.

\section{Anatomía patológica}

Macroscópicamente el hígado es pequeño, nodular, de color amarillento por su gran contenido en pigmentos biliares; por esto se le da el nombre de Atrofia amarilla del hígado. Microscópicamente existe degeneración y necrosis extensa del hepatocito, infiltración celular de los sinusoides $y$ sistema porta $(2,3,7)$.

La autopsia de la paciento fallecida, confirmó el diagnóstico de Hepatitis viral; reveló Atrofia amarilla del hígado, en forma aguda y necrosis hepática masiva.

\section{Tratamiento}

Está basado en el reposo. Medida que consideramos de la mayor impor- 
tancia para la evolución de la enfermedad, aunque para muchos autores no revista tanto interés $(2,3,7)$.

Dieta: Especialmente hipograsa e hiperglúcida; la Hipoproteica en aquellos casos en que se sospeche lesión hepática severa (7).

Para algunos es rutinaria la administración de Vitaminas, especialmente las del Complejo B, C y K (10).

Los antibióticos de amplio espectro en forma profiláctica no se recomiendan, pero se justifica su aplicación con el fin de destruir la flora intestinal; esto es útil en estados que hagan presumir inminencia de coma hepático (7). Se deben prescribir en aquellos pacientes complicados con un cuadro infeccioso, evitando los hepatotóxicos.

El empleo de los Corticoides ha sido muy debatido, como elemento de ayuda en el curso de la enfermedad; se aconseja su administración en casos muy severos, o con tendencia a la cronicidad o se reactive $(2,3,7)$.

Las pacientes tratadas en el IMI recibieron terapia basada en:

Reposo, 10 casos.

Dieta hipograsa, hiperglúcida, normoproteica, 10 casos.

Dextrosa hipertónica, 7 casos.

Complejo B, 7 casos.

Vitamina $K, 4$ casos.

Fue necesaria la administración de Antibióticos en dos casos que presentaron complicaciones (Bronconeumonía, infección urinaria, insuficiencia cardíaca congestiva), uno de los cuales requirió la aplicación de Cardiotónicos.

\section{Comportamiento obstétrico}

Quienes sostienen que el embarazo agrava la Hepatitis en forma considerable son partidarios de interrumpir la gestación (10). Este argumento no es defendido por todos los obstetras $(5,6)$, Nosotros basados en los datos obtenidos no creemos necesario llegar a este procedimiento, sino en casos que no respondan al tratamiento médico y hagan temer un coma hepático.

\section{Profilaxis}

Estará dirigida a evitar el contacto de las mujeres embarazadas con personas sospechosas de padecer la enfermedad o cuando ésta esté francamente declarada. En igual forma debemos abstenernos de prescribir sangre, sueros, vacunas, fibrinógeno, o drogas por vía parenteral cuando no sean estrictamente requeridas. Así mismo debemos velar por la correcta esterilización de los elementos utilizados con este fin.

En época de epidemia o ante la sospecha de un posible contagio se aconseja el uso de gamma-globulina a dosis de $0,1 \mathrm{ml}$. por kilo de peso.

\section{Conclusiones}

1. En nuestro medio la incidencia de Hepatitis asociada al embarazo no es frecuente.

2. Se observa especialmente en multíparas.

3. Tiene tendencia a presentarse en la primera mitad del embarazo.

4. En mayor proporción cursa en forma benigna.

5. La mortalidad sigue siendo alta, pero ésta no difiere de la encontrada en la población general. 
6. No es causa determinante de embriopatías.

7. Es responsable con frecuencia de Abortos, Partos prematuros $y$ Muerte fetal in útero.

8. No parece alterar en forma marcada el curso del parto.

9. Las pacientes consultan en una etapa avanzada de la enfermedad.

10. Los resultados de laboratorio concuerdan con los autores revisados y son similares a los obtenidos en la mujer no embarazada.

11. Consideramos el reposo como medida fundamental en el tratamiento.

12. Dada la tendencia de la enfermedad al curso benigno, no se justifica interrumpir el embarazo.

13. Con buena atención prenatal, evitando el uso de tratamientos innecesarios y fomentando las campañas de salubridad, reduciremos al mínimo las enfermedades infectocontagiosas, redundando esto en beneficio para la mujer embarazada y su descendencia.

\section{BIBLIOGRAFIA}

1 BOTELLA-LLUSIA: Obstetricia. 7a. ed. 11, 54.

2 CARBONE, U. J., cols.: Diagnóstico y tratamiento, edit. $364,1965$.

3 CECIL-LOEB: Tratado de Medicina Interna, edit. Interamericana. 1a. ed. 1964, 11: 1.015 .
4 EASTMAN, N. J.: Williams Obstetrics, Ed. 11 Appleton century crofts, Inc. New York 777, 1956.

5 FIRPO, J.: Hepatitis gravídica, Bol. Soc. O. G. Bs. As. 35: 126, 1956.

6 GREENHILL, J. P.: Obstetrics, Ed. Saunders Cía. Philadelphia, 1955.

7 HARRISON, T. R.: Medicina Interna. 3a. ed. 1965.

8 INGERSLER, M. y TEILUM, G.: Jaundice during pregnancy. Acta Obst. et Gynec. Scandinav 31: 74, 1951.

9 MARTINI, R. Y FERGUSON, F. C.: Infections hepatitis associated with pregnancy. New England J. Med. 237: 114, 1947.

10 LEON JUAN: Tratado de Obstetricia. Ed. Fernández, Bs. As. 1967, 11: 36.

11 MICKAL, D.: Infections hepatitis in pregnancy. Am. J. Obst. \& Gynec. 62: 409, 1951.

12 ROSZKOWSKI, y cols.: Jaundice in pregnancy. Am. J. Obst. \& Gynec. 102: 839, 1968.

13 ROSZKOWSKI, 1. y cols.: Jaundice in pregnancy, Am. J. Obst. \& Gynec. 101: 500, 1968.

$14 \mathrm{ROTH}$, L. G. : Infections hepatitis in pregnancy. Am. Sc. 225: 139, 1953.

15 ROVINSKY, J. J., y GUTTMACHER, F. A. : Complicaciones Médicas, Quirúrgicas, Ginecológicas en el Embarazo. 2a. ed. 1967.

16 ROVINSKY, J. J. y cols. Op. cit. 459.

17 THRORLING, L.: Jaundice in pregnancy, Acta Obst. et Gynec. Scandinav. 302: 151, 1955.

18 ZONDEK, B., Y BROMBERG, Y. M.: nfections hepatitis in pregnancyl J. Mt. Sinai Hostp. 14: 222. 1957. 